\title{
Bad gene expression following effect of coenzyme Q10 on Wistar rat hippocampus with cerebral ischemia
}

\author{
Farnoosh Kazemi Asafeh ${ }^{1}$, Maliheh Entezari ${ }^{2}$, Maryam Shirvani Shahenayati ${ }^{1}$ \\ ${ }^{1} \mathrm{MSc}$ in Molecular Genetics, Department of Biology, Islamic Azad University, Damghan Branch, Damghan, Iran \\ ${ }^{2}$ Associate Professor, Department of genetics, Tehran Medical Sciences, Islamic Azad University, Tehran, Iran
}

\begin{abstract}
Background: Q10 coenzyme is a potent antioxidant in the mitochondrial membrane. Releasing the oxygen free radicals occurs in the cerebral ischemia. Using Q10 coenzyme causes strength against oxidative after injury of cerebral ischemia during reperfusion. Also CoQ10 plays an important anti-apoptotic role to reduce Caspase 3 as a key enzyme neuroprotective in apoptosis. According to the sensitive nature of CA1Hypocampus pyramidal neurons against the cerebral ischemia, we studied the effects of CoQ10 in this area of rat's brain after transient general ischemia/ reperfusion.

Materials and methods: We selected randomly 24 heads of Wistar rats under 250-300 g weights that divided into 4 groups, including control, experiment (ischemia, Q10), ischemia and Q10 coenzyme groups. Then we separated the hippocampus from the brain expression of pro-apoptosis genes was studied. After extraction of RNA and synthesis of cDNA, we used real time RCR methods to express this gene.

Results: The expression of Bad gene in experiment group $(\mathrm{Q} 10,10 \mathrm{mg} / \mathrm{Kg})$ significantly decreased compared to ischemia group $(\mathrm{p}<0.05)$.

Conclusion: It seems that ischemia caused to increase the expression of Bad pro-apoptic gene, and CoQ10 with dose of $10 \mathrm{mg} / \mathrm{Kg}$ has effects on the expression of Bad gene and prevent the severity of lesions.

Keywords: CoQ10, Apoptosis, Hippocampus, Real Time PCR.

Cited as: Kazemi Asafeh F, Entezari M, Shirvani Shahenayati M. Investigation of Bad Gene Expression Following Coenzyme Q10 Effect with Ischemia in Wistar Rat Hippocampus. Medical Science Journal of Islamic Azad University, Tehran Medical Branch 2019; 29(4): 296-302.
\end{abstract}

Correspondence to: Maliheh Entezari

Tel: +989127796007

E-mail: mentezari@iautmu.ac.ir

ORCID ID: 0000-0003-4191-3351

Received: 3 Dec 2018; Accepted: 26 Feb 2019 
مجله علوم يزشكى دانشگاه آزاد اسلامى

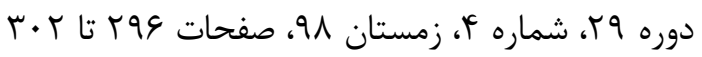

Original

Article

\section{بررسى تغيير بيان زن Bad متعاقب تاثير كوآنزيم Q10 يس از ايسكمى مغزى در هيبو كامي موش صحرايى ويستار نر}

فرنوش كاظمى اسفه'، مليحه انتظارى'، مريم شيروانى شاه عنايتى'

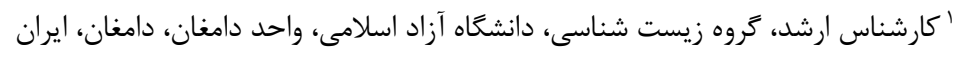

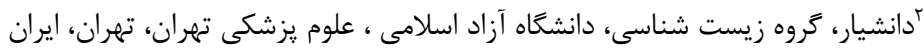

جكيده

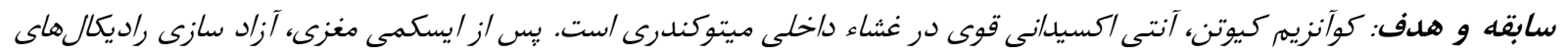

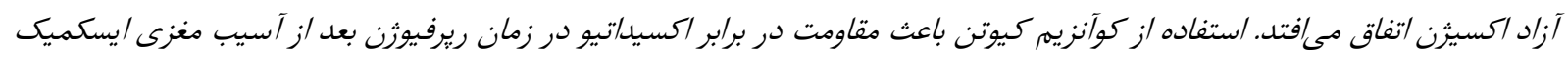

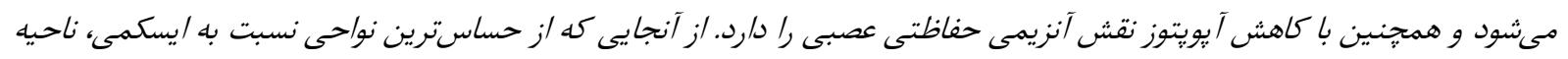

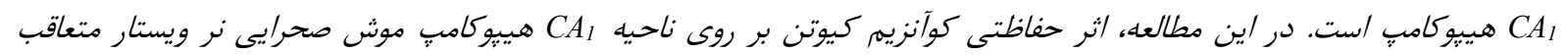

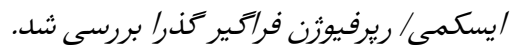

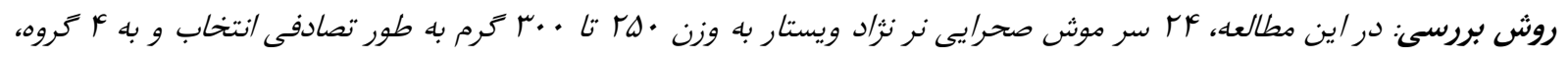

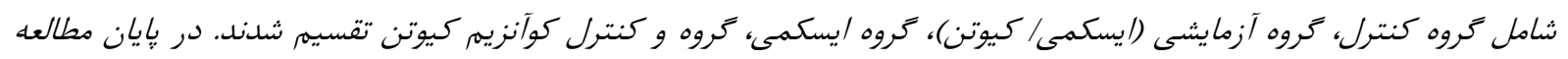

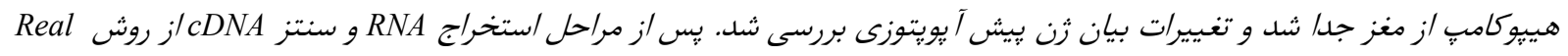
time PCR

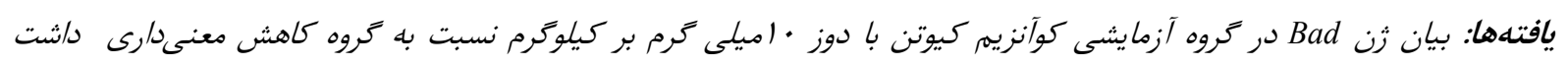
. $(p<\bullet / \cdot \Delta)$

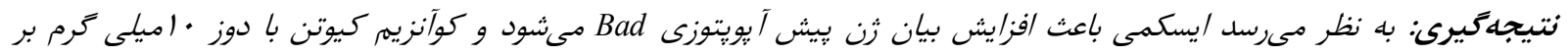

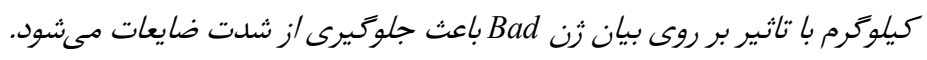

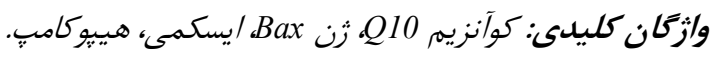

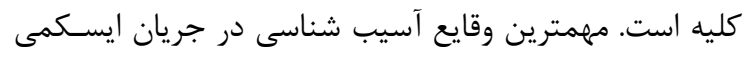
مقدمه

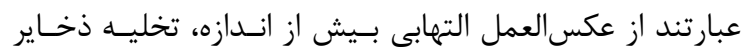

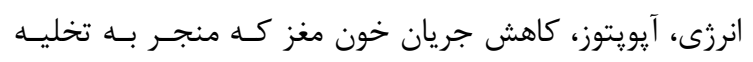

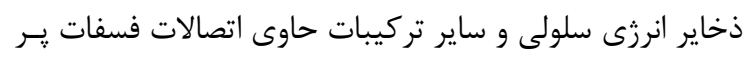

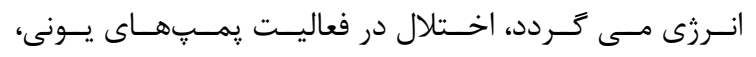

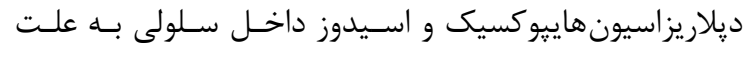

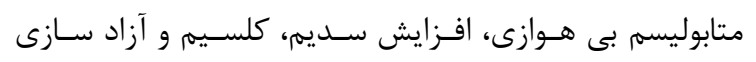

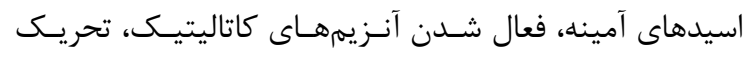

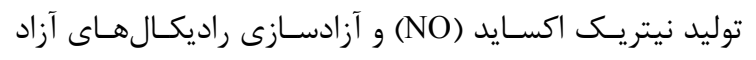

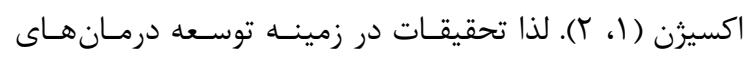
ايسكمى / يرفيوزن آسيب بافتى است كـهـ هـس از يـك دو راه

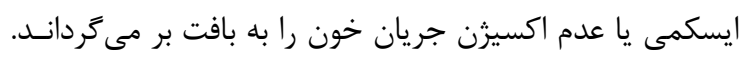

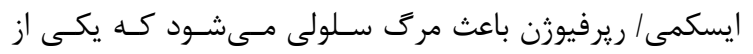

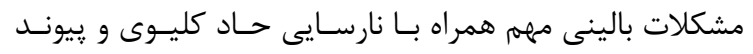

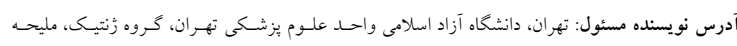
انتظارى (email: mentezari@iautmu.ac.ir)

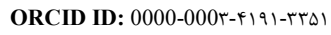
تاريخ دريافت مقاله: IV/A/IT

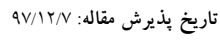




\section{مواد و روشها كروههاى حيوانات}

كَروه هاى حيوانى با رعايت كردن كليه اصول اخلاقى كـار بـاــات

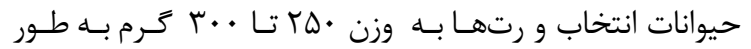

تصادفى به \& كروه 9 تايى تقسيم شدند: .

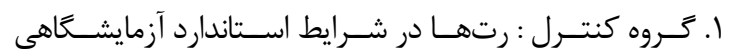

نكَهدارى شده و در بايان مدت موردنظر (9 ورز) كشته شدند.

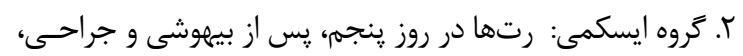

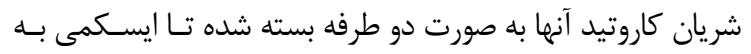

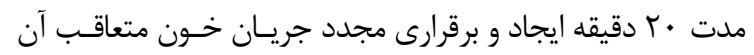

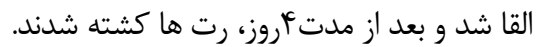

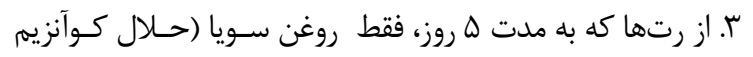

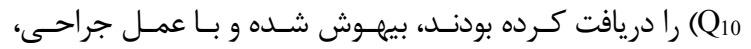

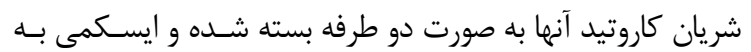

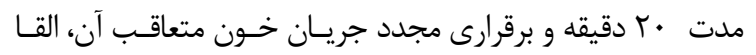

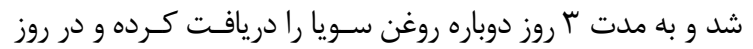
جهارم بعد از ايسكمى (روز نهم) كشته شدند.

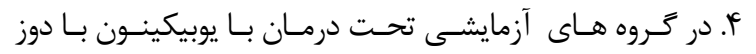

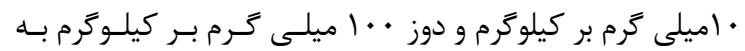

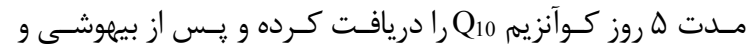

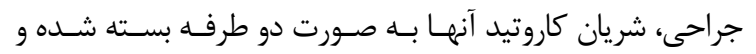

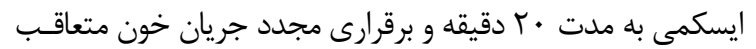

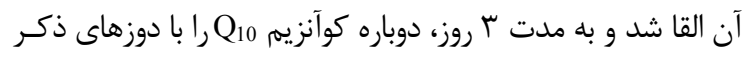

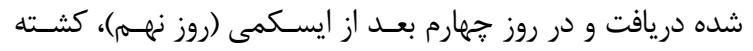
شدند و هييوكامب آنها مورد بررسى قراركرفت. استخراج RNA و سنتز CDNA.

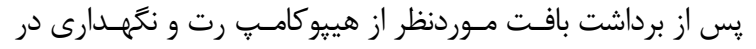

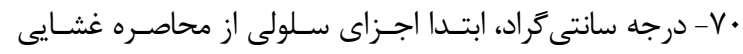
خارج شد و سيس به روش ترايزول RNA استخراج و براى صحت التحري

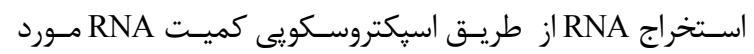

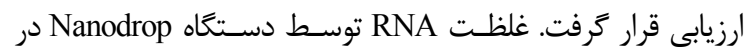

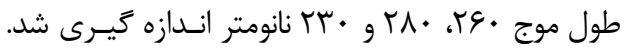
طيف جـذبى 260/280 A خلوص (عـدم آلـودىى با يــروتئين) و و

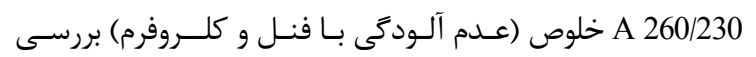

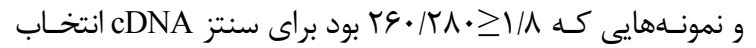

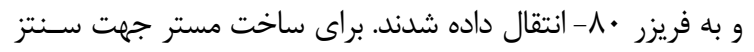
طبق دستور كيت شركت سيناكلوناز استفاده شد.
حفــاظتى عصـبى (Neuroprotective) ضــرورى هسـتند تـا

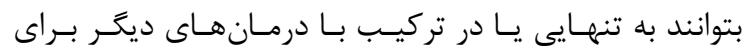

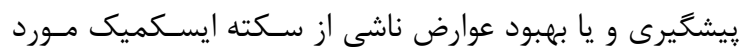

استفاده قرار كيرند (بآ).

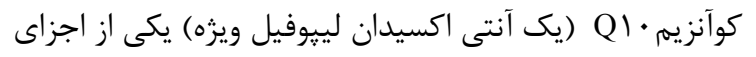

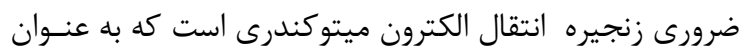

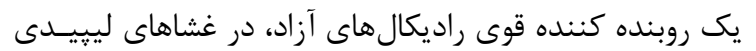

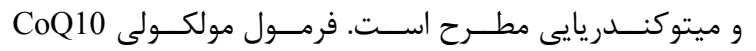
و وزن مولكولى آن $\mathrm{C}_{59} \mathrm{H}_{90} \mathrm{O}_{4}$ ،

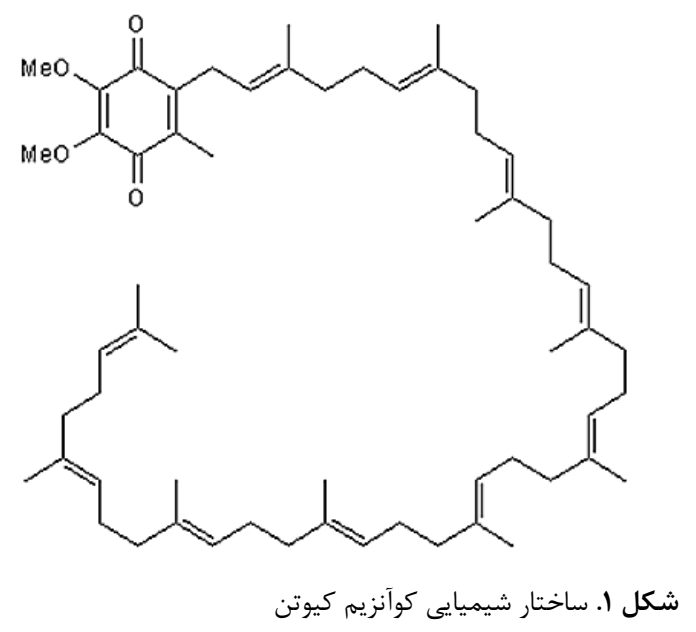

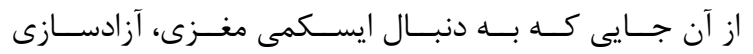
راديكال هاى آزاد اكسيرن اتفاق مىافتد، لذا با ترميم يِيامدهاى

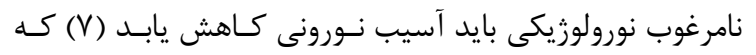

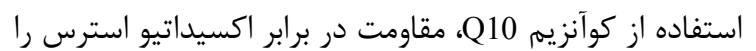

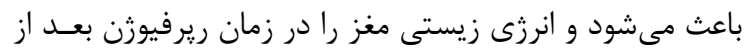

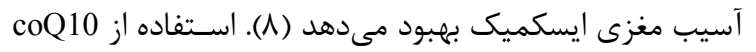

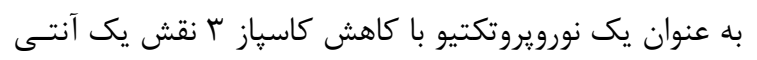

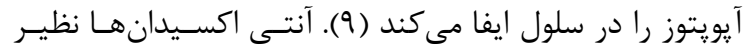

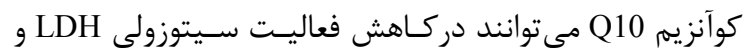

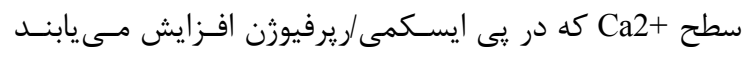

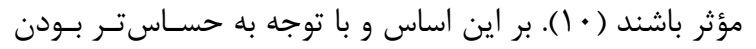

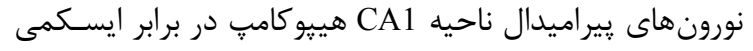

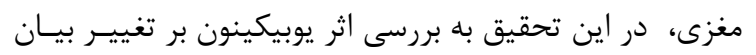

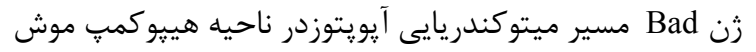

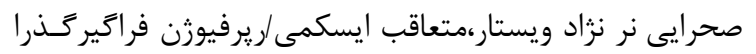

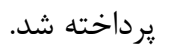


اختصاصى بودن يرايمرهــا و نمـايش طــول قطعـات تكثيـر شـده، نمونهها به زل يلى آكريل آميد منتقل شدند.

\begin{tabular}{|c|c|}
\hline زمان ( ثانيه ) & دما \\
\hline 10 & $9 \Delta$ \\
\hline 4. & 4. \\
\hline 10 & $9 \Delta$ \\
\hline
\end{tabular}

تحليل آمارى

تحليل دادهها توسط نرم افزار آمـارى rest جهـت مقايسـه بيـان و نسبتها انجام شد.

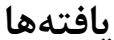
تاييد صحت يرايمر

شكل r نشان دهنده طول صحيح وتك باندبودن قطعات تكثيرشده با يرايمرهاست (طول قطعه زن Bad و طول فندان

قطعه Gapdh).

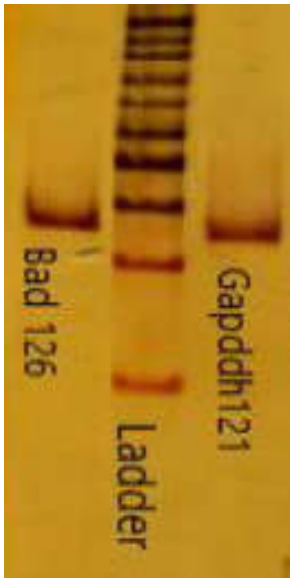

شكل r. نتيجه PAGE براى تكثيرنمونه كنترل با يرايمر

منحنى استاندارد با بازده 99 درصد براى زن Gapdh و

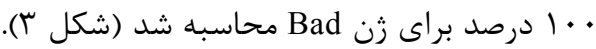

$$
\text { آناليز منحنى ذوب (تفكيك) }
$$

منحنى ذوب بيانكر محصولاتى است كه طى واكنش PCR تكثير مىشوند. به دليل تك قلهاى بودن تكثير اختصاصى قطعات رنى مورد نظر، عدم جفت شدن يرايمرها و عدم برد تكثير قطعات غير اختصاصى براى هر زن با استفاده از

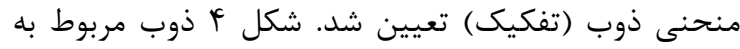

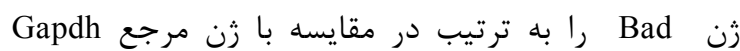

$$
\text { نشان مى نهد. }
$$

يرايمرها بـه كمـك نـرم افـزار Generunner و 3 Primer طراحسى 3

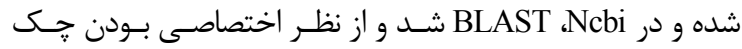

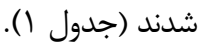

\begin{tabular}{|c|c|c|c|c|}
\hline 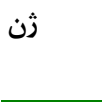 & توالى يرايمر & ذدماى & $\begin{array}{c}\text { طp } \\
\text { bp }\end{array}$ & $\begin{array}{c}\text { درصد } \\
\text { CG }\end{array}$ \\
\hline $\mathrm{adF}$ & GGAGCATCGTTCAGCAGCAG & $\Delta \mathrm{N} / \cdot$ & r. & 4. \\
\hline ad $R$ & CCATCCCTTCATCTTCCTCAGTC & $\Delta V / \varphi$ & ז & $\Delta T / T$ \\
\hline apdh F & AAGTTCAACGGCACAGTCAAGG & $\Delta \mathrm{V} / \mathrm{A}$ & tr & $\Delta$. \\
\hline ind R & CATACTCAGCACCAGCATCACC & $\Delta S / V$ & tr & $\Delta F / \bar{Q}$ \\
\hline
\end{tabular}
جدول ا. توالى يرايمر طراحى شده Bad و Gapdh

Real time PCR

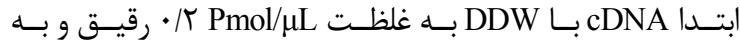

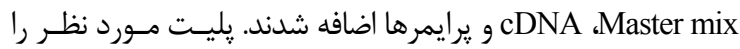

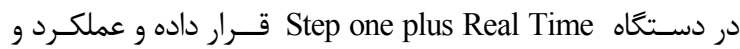
اختصاصت يرايمرها جـى شــند. زن Bad بـه عنـوان زن هـدف و

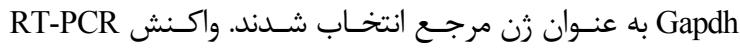
براى زن هدف و مرجع در نمونهاى كنترل و تست به صورت ســه تايى در يليت و9 خانهاى انجام شد. برنامه زمانى و دمايى واكـنش ABI step one plus Real مـدل RT PCR در دسـتخاه PCR

\begin{tabular}{|c|c|c|}
\hline برئ & زمان & las \\
\hline 1 & $10^{\prime}$ & $90^{\circ}$ \\
\hline \multirow[t]{2}{*}{ 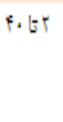 } & $10^{\prime \prime}$ & $90^{\circ}$ \\
\hline & q." & 94 \\
\hline
\end{tabular}
Time PCR

در مرحله دوم منحنى ذوب تشكيل شد .مراحل فـوق بـراى عـدم

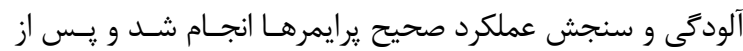

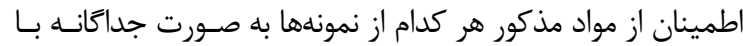
يرايمر جهت بررسى بيان زن در خاهكها در دستگاه قرار گرفتنـد.

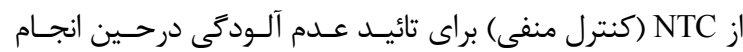
آزمايش استفاده شد. كنترل منفى فاقد cDNA بود. جدول ب برنامه زمانى ودمايى PCR در مرحله دوم براى سـنجش

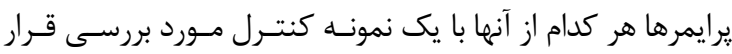

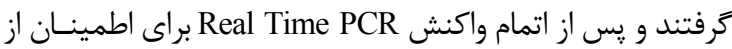




\section{بيان زن Bad و آناليزهاى آمارى}

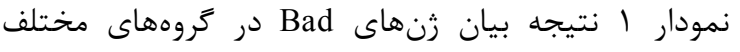
نسبت به كنترل را نشان مى دهد.

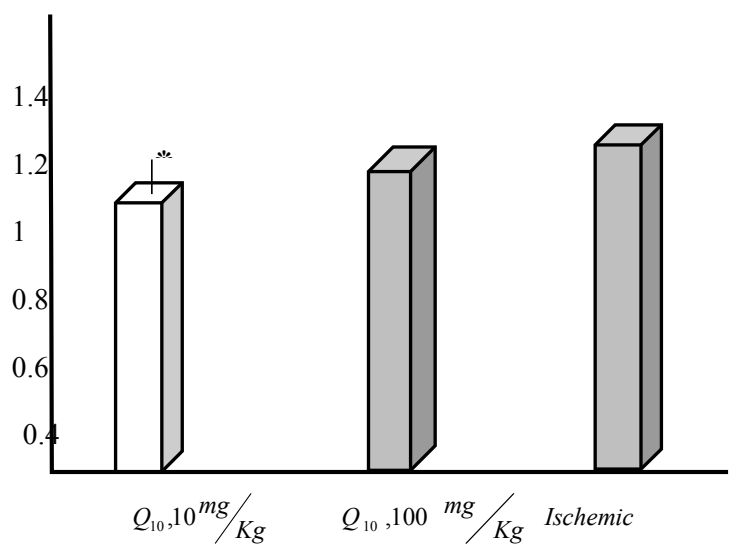

نمودار ا. نسبت بيان زن BAD دركروهاى مختلف نسبت به كنترل

بحث

تاكنون استراتزى موثرى با معضل ايسكمى پيدا نشده است

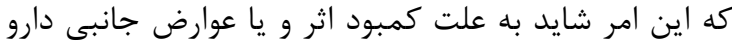
است. اخيرا استفاده از يوبيكينون به عنوان يك استراتزى بنى

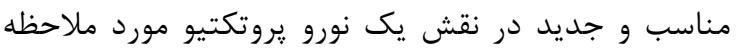
قرار كرفته است (V). كوآنزيم Q10 دارويى است كه اثبات شده است مقاومت در

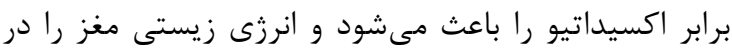
زمان ريرفيوزن بعد از آسيب مغزى ايسكميك بهيبود

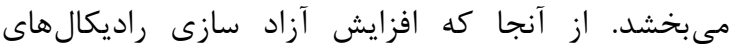

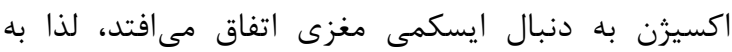

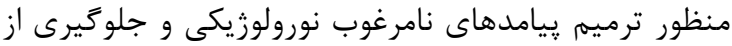

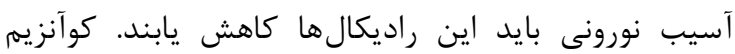

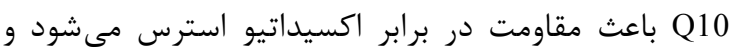

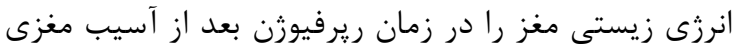

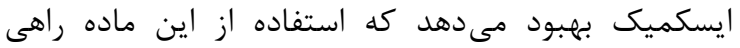
منطقى به نظر مىرسد. آنتى اكسيدانها نظير كوآنزيم

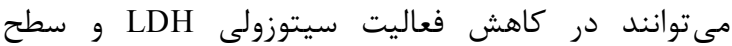
كلسيم كه در يى ايسكمى/ ريرفيوزن افزايش مى يابند موثر

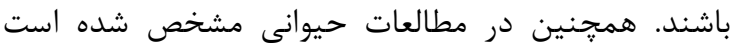

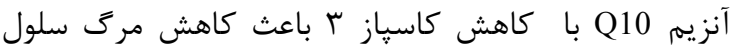
مىشود كه به عنوان يك نورويروتكتيو مطرح مىشود (9).

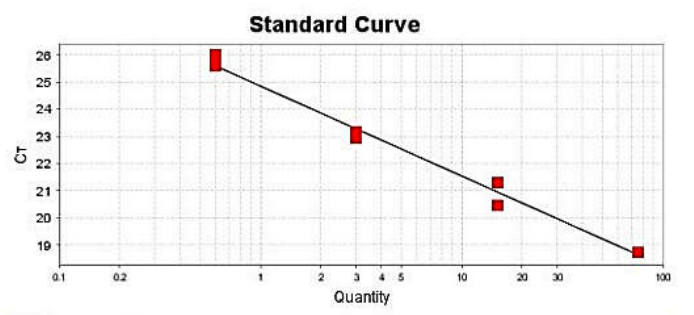

Standard $\square$ Unknown $\square$ Unknown (Flagged)

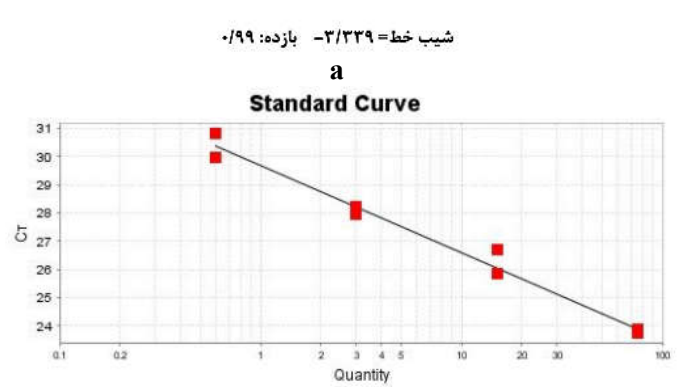

Standard Unknown Unknown (Flagged)

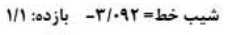

b

شكل r. منحنى استاندارد مربوط به زنهاى (a)Bad Gapdh و

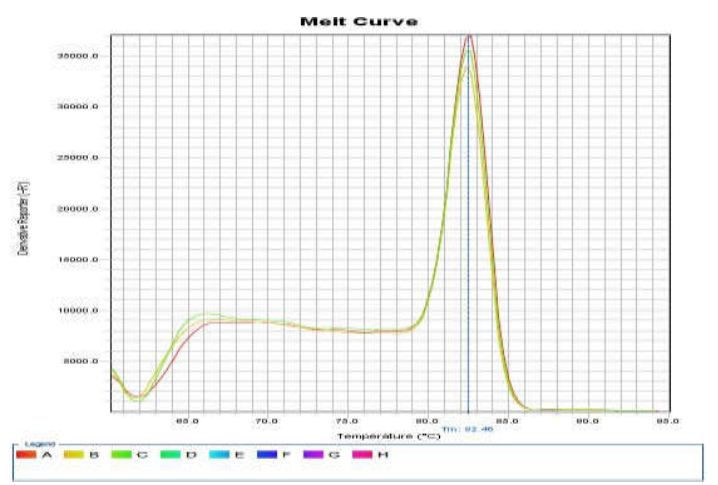

a
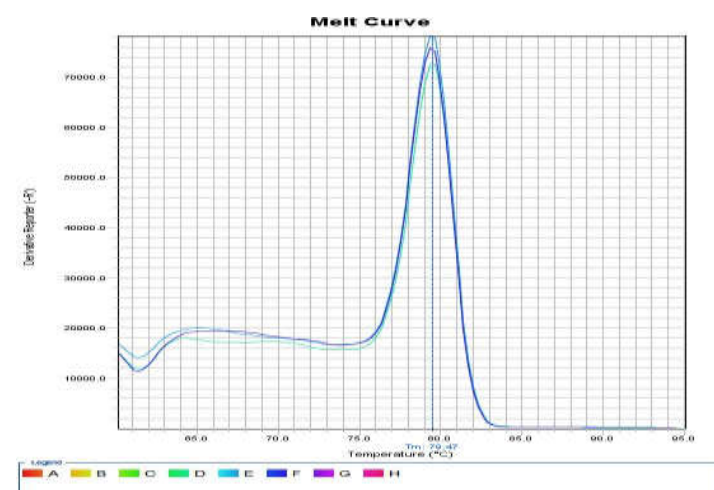

b

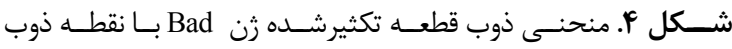

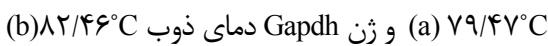


درخصوص نقش اعضاى خانواده Bc12 در آسيب ايسكميك

مغز مشخص شده است كه تظاهر مقدار بالاى Bc12 يا

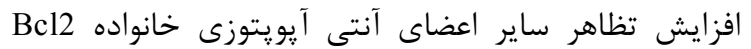
مثل Bcl xl از آيوريتوز نورونى ميى كاهد. رهايى سيتوكروم از ميتوكندرى يس از ايسكمى به علت فعاليت Bax و و ساير اعضاى يرو آيويتوتيك خانواده Bc12 به وجود ميى آيد. افزايش سطح Bax به سرعت از سيتوزول به ميتوكندرى نقل مكان مى كند (If) (li).

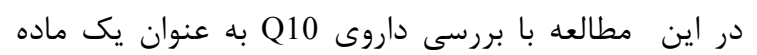

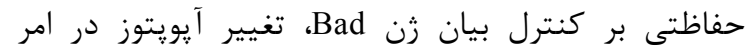

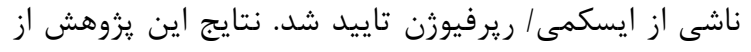
تاثير ايسكمى بر افزايش بيان زن Bad حكايت داشت و و

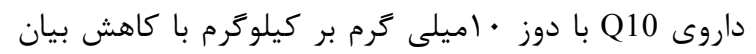
زن Bad از شدت ضايعات جلو خيرى كرد.
زن Bad يك زن ييش آيويتوزى است كه مسير را به سمت

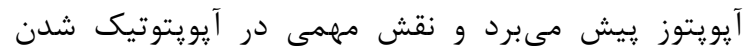

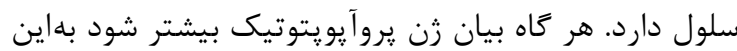
معناست كه سلول به سمت آيويتوز هدايت مى شود. هيج

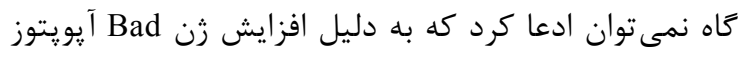

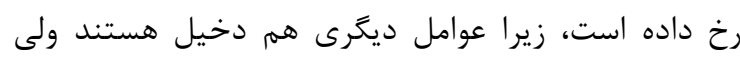
مى توان به اين نتيجه رسيد كه يك زن زيش ريش برنده آيوريتوز

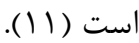
مشخص شده است با غيرفعال كردن جهش رن زيش آيويتوزى Bad فعاليت آيویتوز كاهش يافته و در نتيجه مرى سلولى نيز كاهش مىيابد (Y) (I). با بررسى ميزان بيان

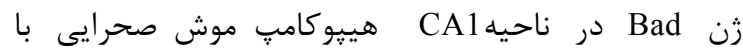
استفاده از داروى نوروتوروفيك مشخص شد كه بيان زن BAD بعد ازاستفاده نوروتوروفيك كاهش مى يابد ( (1، سا).

\section{REFERENCES}

1. Badr R, Hashemi M, Javadi G, Movafagh A, Mahdian R. Assessment of global ischemic/reperfusion and Tacrolimus administration on CA1 region of hippocampus: gene expression profiles of BAX and BCL2 genes. Bratisl Lek Listy 2016;117:358-62.

2.Badr R, Hashemi M, Javadi G, Movafagh A, Mahdian R. Gene Expression Profiles of BAD and Bcl-xL in the CA1 Region of the Hippocampus Following Global Ischemic/Reperfusion and FK-506 Administration. Iran Red Crescent Med J 2015;17:e23145.

3. Behroozaghdam M, Hashemi M, Javadi G, Mahdian R, Soleimani M. Expression of bax and bcl2 Genes in MDMAinduced Hepatotoxicity on Rat Liver Using Quantitative Real-Time PCR Method through Triggering Programmed Cell Death. Iran Red Crescent Med J 2015; 26:17:e24609.

4.Ishrat T, Khan MB, Hoda MN, Yousuf S, Ahmad M, Ansari MA, et al. Coenzyme Q10 modulates cognitive impairment against intracerebroventricular injection of streptozotocin in rats. Behav Brain Res 2006; 171: 9-16.

5.Gholnari T, Aghadavod E, Soleimani A, Hamidi GA, Sharifi N, Asemi Z. The Effects of Coenzyme Q10 Supplementation on Glucose Metabolism, Lipid Profiles, Inflammation, and Oxidative Stress in Patients With Diabetic Nephropathy: A Randomized, Double-Blind, Placebo-Controlled Trial. J Am Coll Nutr 2018;37:188-93.

6.Awad AM, Bradley MC, Fernández-Del-Río L, Nag A, Tsui HS, Clarke CF. Coenzyme Q10 deficiencies: pathways in yeast and humans. Essays Biochem 2018;62:361-376.

7.Kalayci M, Unal MM, Gul S, Acikgoz S, Kandemir N, Hanci V, et al. Effect of Coenzyme Q10 on ischemia and neuronal damage in an experimental traumatic brain-injury model in rats. BMC neuroscience. BMC Neurosci 2011;12:75.

8.Horecký J, Gvozdjáková A, Kucharská J, Obrenovich ME, Palacios HH, Li Y, et al. Effects of Coenzyme Q and Creatine Supplementation on Brain Energy Metabolism in Rats Exposed to Chronic Cerebral Hypoperfusion. Curr Alzheimer Res 2011; 8: 868-875.

9.Young AJ, Johnson S, Steffens DC, Doraiswamy PM. Coenzyme Q10: a review of its promise as a neuroprotectant. CNS spectrums 2007; 12: 62-68.

10.Hashemi M. The Study of Pentoxifylline Drug Effects on Renal Apoptosis and BCL-2 Gene Expression Changes Following Ischemic Reperfusion Injury in Rat. Iran J Pharm Res 2014; 13: 181-89.

11.Farahani K, Hashemi M. Investigating the Effect of Hydroalcoholic Extract of Cyperus rotundus L. on the Expression of Bcl-x1 Antiapoptotic Gene in Rats' Hippocampus Tissue Following Global Ischemic-Reperfusion Injury. Acta Medica Iranica 2016;54:256-60.

12.Khazaei Koohpar Z, Entezari M, Movafagh A, Hashemi M. Anticancer activity of curcumin on human breast adenocarcinoma: Role of Mcl-1 gene. Iran J Cancer Prev 2015;8:1-4. 
13.Sharifi ZN, Abolhassani F, Zarrindast MR, Movassaghi S, Rahimian N, Hassanzadeh G. Effects of FK506 on hippocampal CA1 cells following transient global ischemia/reperfusion in Wister rat. Stroke Res Treat 2012;2012:809417.

14.Sari S, Hashemi M, Mahdian R, Parivar K, Rezayat M. The effect of pentoxifylline on bcl-2 gene expression changes in hippocampus after ischemia-reperfusion in Wistar rats by a quatitative RT-PCR method. Iran J Pharm Res 2013; 12: 495-501. 